\title{
Acid Stabilization of Fly Ash from Coal Fired Power Plants
}

\author{
Wei Xiang ${ }^{a}$, Ying Li $^{b}$ \\ School of Environmental Engineering, Xuzhou Institute of Technology, Xuzhou 221111, China \\ axiangwei0229@163.com, bly131015@163.com
}

Keywords: fly ash; stabilization; heavy metals; phosphoric acid

Abstract. Heavy metals chemical stabilization with phosphoric acid was assessed for two kinds of fly ash in order to transform available heavy metals into insoluble metal phosphate compounds and reduce the risk to the environment. The behavior of heavy metals in the liquids and solids samples were both investigated. And $\mathrm{pH}$, time and mass percentages of added phosphoric acid were as experimental parameters in this study. Three acid mass percents were analyzed for the two kinds of samples separately. Phosphoric acid reacted rapidly and $75 \%$ phosphoric acid was consumed during the 5 minutes at the beginning of the reaction. Arsenic and the other 8 heavy metals, such as $\mathrm{Cr}, \mathrm{Pb}$ and $\mathrm{Zn}$ as the mainly elements were monitored during the $4 \mathrm{~h}$ of reaction. The results showed that the elements concentrations in the liquid increased with the increase of phosphoric acid, the content decreased in the solid after the experiment, the mobility of heavy metals should depend on the acidity of the solution and the nature of the solids formed at the end of the stabilization.

\section{Introduction}

Fly ash is the main byproducts of the coal-fired power plants, which has been classified as a hazardous waste due to its higher concentration of heavy metals [1]. Because the heavy metals leached from fly ash could be into the environment and pollute it when the fly ash is not disposed. Research the behavior of heavy metals from fly ash treated can help to understand the transfer and reaction rules of the metals in fly ash.

Fly ash can be treated by several methods, such as physical and chemical methods. The most frequent disposal way of fly ash is chemical stabilization, which is one method of reducing the leachability of heavy metals in the fly ash[2]. Phosphoric acid and ferrous/ferric sulfate solution are usually used as agents in the stabilization, which can react with the metals in the fly ash and reduce the leaching risk of the metals to the environment [3-5].

Stabilization technology is widely used for treatment of hazardous wastes, although it has not been tested on fly ash. Sukandar [6] , using chelating agents and phosphates for stabilization purposes, analyzed the behavior of heavy metals and carried out an ecotoxicity evaluation on medical waste. Bradley S. Crannell [2] studied heavy metal stabilization in municipal solid-waste-combustion bottom ash by using a soluble phosphate. Hu Shaohua [7] used a mixed ferrous/ferric sulfate solution and performed stabilization tests for heavy metals in municipal solid-waste incineration ash.

Phosphoric acid was applied to stabilize the two different kinds of fly ash in this study. The research focused on the distribution of the heavy metals in the solids, and the effect of the stabilization experiment to the behavior of the heavy metals.

\section{Materials and methods}

Fly ash samples. The two kinds of fly ash used in this investigation were sampled from two different power plants in Xuzhou of China. One sample came from the plant used pulverized coal fired boiler and limestone-gypsum wet flue gas desulfurization technology, sample name was defined as $\mathrm{xt}$; the other sample came from the plant used circulating fluidized bed boiler and added desulfurization agent in the progress of combustion, sample name was defined as $\mathrm{hm}$. The particle size distributions of the fly ash were both below $200 \mu \mathrm{m}$, and the content of granule range from $3 \mu \mathrm{m}$ to $90 \mu \mathrm{m}$ was more than $80 \%$. The specific surface areas were $1.015 \mathrm{~m}^{2} / \mathrm{g}$ and $0.865 \mathrm{~m}^{2} / \mathrm{g}$ for xt and $\mathrm{hm}$ respectively. 
Methods and analytical techniques. A batch reactor was used to follow the phosphoric acid react with the fly ash. The temperature was controlled at $20^{\circ} \mathrm{C}$ and rotational speed was controlled at 400 rpm. Experimental parameters included $\mathrm{pH}$, time and mass percentages of added phosphoric acid.

fly ash was added in deionised water in the batch reactor, in order to obtain a solid fraction content of $35 \%$, previously determined to be optimal for homogenous mixing by a rheological study [4]. Phosphoric acid was added when the suspension was homogenized, and the acid mass percentages were $3 \%, 5 \%, 10 \%$ separately for the two kinds of fly ash. Samples were got at $5 \mathrm{~min}, 10 \mathrm{~min}, 30 \mathrm{~min}$, $60 \mathrm{~min}, 90 \mathrm{~min}, 120 \mathrm{~min}, 180 \mathrm{~min}, 240 \mathrm{~min}$ after added the phosphoric acid in the mixing and filtered immediately at 0.45 microns filter membrane. The filtrates were analyzed by ICP and ion chromatograph for heavy metals and anions. The filtered solids were dried in an oven at $40^{\circ} \mathrm{C}$ for $48 \mathrm{~h}$.

\section{Results and discussion}

pH evolution during the stabilization. When the fly ash and deionised water were mixed, the $\mathrm{pH}$ values of the two homogenous mixing were both near 12. But when the phosphoric acid was added, $\mathrm{pH}$ of the mixing decreased rapidly, reduced to $4,2,1$ at added $3 \%, 5 \%, 10 \%$ acid separately for the two samples. The $\mathrm{pH}$ of the suspension had no more changes after five minutes of the reaction. Final $\mathrm{pH}$ depended on the amount of added phosphoric acid. And during the phosphoric acid introduction, gas was immediately observed and lasted for the first few minutes of the reaction, and added more acid, the more gas was produced. Other researchers found that the gas was carbon dioxide during the phosphate reaction[8].

Heavy metals behavior in the liquids and solids samples. Except the heavy metals, As element also detected in the research. Concentrations of $\mathrm{As}$ and $\mathrm{Cr}$ in the liquids with the time were analyzed; while the other heavy metals, such as $\mathrm{Cr}, \mathrm{Pb}$ and $\mathrm{Zn}$ as the mainly elements were concerned in the final liquids and solids in this study.

The results showed that added 5\% acid, the effect of the stabilization was the best for xt fly ash, and $3 \%$ for hm fly ash. So added 5\% percent acid was appropriate in the process of treated the fly ash.

But for all elements, the concentrations tended to increase with phosphoric acid. It mainly due to that the acid treatment should affect soluble element distributions because of $\mathrm{pH}$ function. And the final mobility of heavy metals should depend on the nature of the solids formed at the end of the stabilization

Compare the content of heavy metals in the fly ash before and after the stabilization. The composition of heavy metals in final solid samples was detected after the stabilization. And the elements compositions of the fly ash before and after the stabilization test were compared, that is shown in Fig.1.
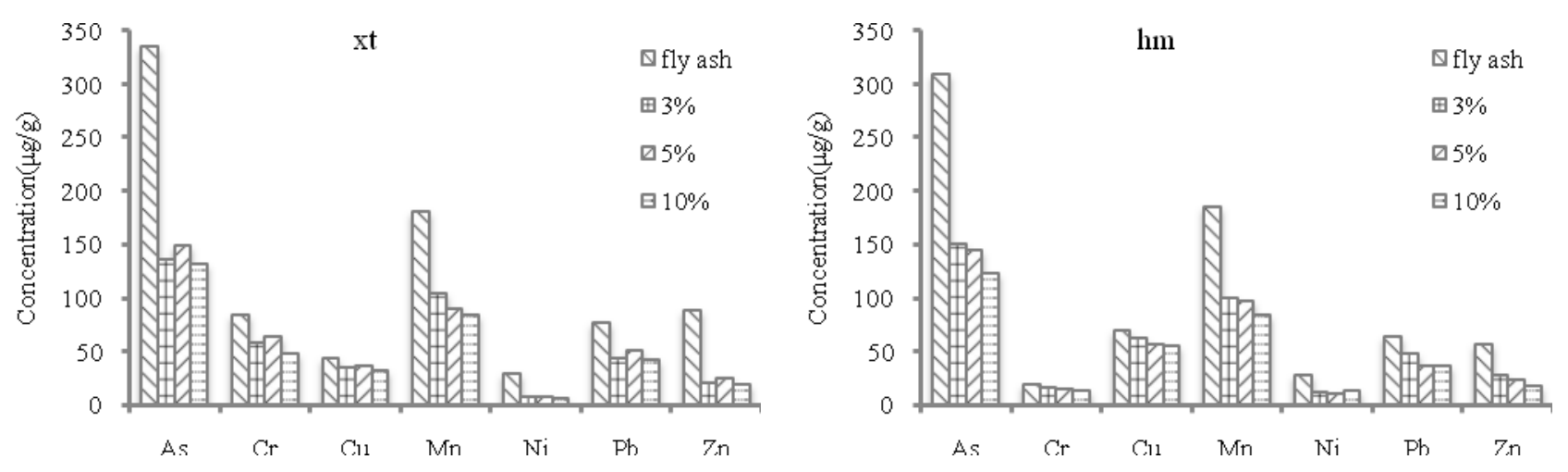

Fig.1 Comparison of the heavy metals content in solid samples

For the two samples, $\mathrm{Cd}$ and $\mathrm{Hg}$ were not detected in the final solids, and the concentration of the other elements decreased after the experiments, and with the increase of the phosphoric acid, the concentration of the metals decreased obviously. As, Mn, Zn decreased more than 50\% compared with the content of the fly ash, while $\mathrm{Cr}, \mathrm{Cu}$ decreased slightly. The results illuminated that the heavy 
metals in fly ash reacted with the phosphoric acid and could form complex orthophosphates, so the content reduced after the experiment. And for the As, Mn and $\mathrm{Zn}$, they were more easily combined with phosphoric acid than $\mathrm{Cr}$ and $\mathrm{Cu}$. Therefore the reaction of fly ash with phosphoric acid is an efficient way to stabilize the metals in fly ash.

Phosphate reaction. The initial concentrations of phosphoric acid were the same at the same percentage in the two kinds of fly ash mixing. And the acid reacted with the mixing rapidly, the concentrations of the $\mathrm{PO}_{4}{ }^{3-}$ reduced sharply. Nearly $75 \%$ phosphoric acid was consumed during the 5 minutes at the beginning of the reaction. Then the acid consumed rate slowed down progressively until the acid reacted completely is shown in Fig.2.
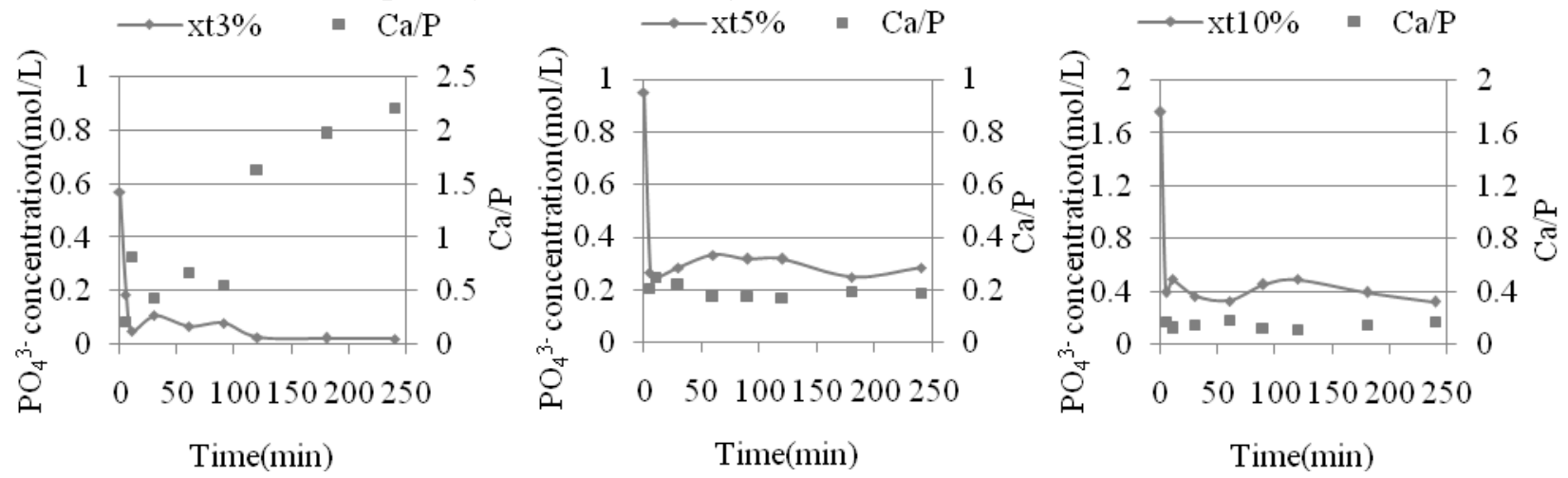

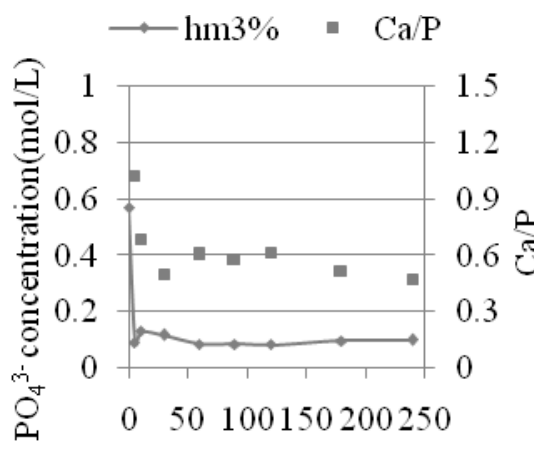

Time(min)
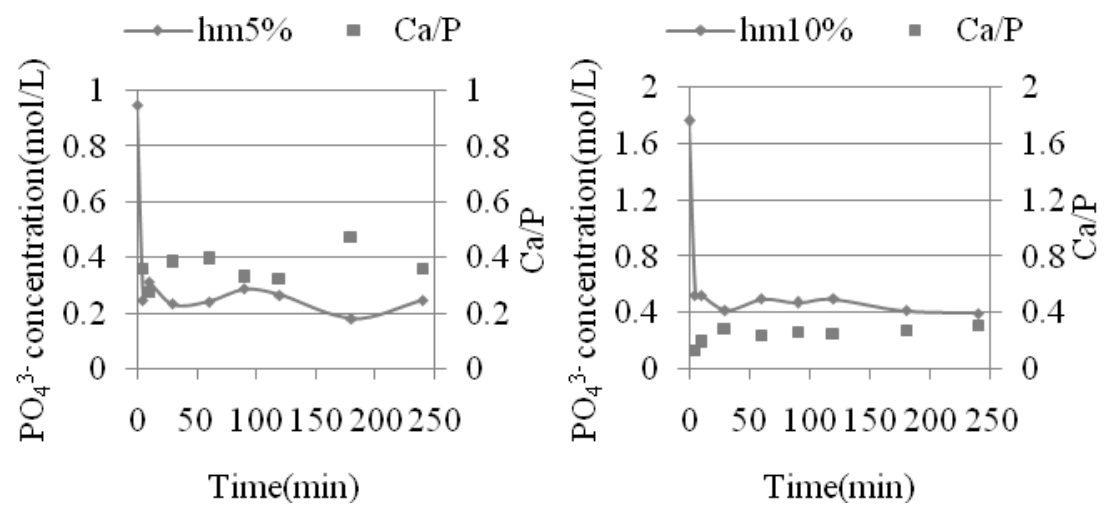

Fig. $2 \mathrm{PO}_{4}{ }^{3-}$ concentration and $\mathrm{P} / \mathrm{Ca}$ values during the stabilization for the two samples

In Fig.2, $\mathrm{P}$ represents the concentration of $\mathrm{PO}_{4}{ }^{3-}$ in the solution. $\mathrm{Ca} / \mathrm{P}$ value was an important index in the stabilization experiment. When the $\mathrm{Ca} / \mathrm{P}<1.67$, there are mainly soluble phosphate in the solution; while the $\mathrm{Ca} / \mathrm{P}>1.67$, there will form stable $\mathrm{Ca}-\mathrm{HAP}$ and with the best condition to remove and stabilize the heavy metals in the solution. But in my study, the $\mathrm{Ca} / \mathrm{P}$ values were 0.2 in $\mathrm{xt}$ samples with the time except xt3\% samples, and the values were $0.4 \mathrm{in} \mathrm{hm} \mathrm{samples} \mathrm{during} \mathrm{the} \mathrm{experiments.}$ The values were less than 1.67, the results showed that the heavy metals dissolved in the solution and formed soluble phosphate in these samples. However, in xt3\% samples, when the experiment continued $90 \mathrm{~min}$, the $\mathrm{Ca} / \mathrm{P}$ value increased and higher than 1.67 , then the heavy metals could be well stabilized in the fly ash.

\section{Conclusions}

Two kinds of fly ash were treated by phosphoric acid and the behavior of heavy metals in the fly ash was analyzed. The metals in fly ash reacted with acid and formed the more stable heavy metal-stabilizing compound complexes and, hence, reduced the risk to the environment. Acid stabilization affected heavy metals and led them as inclusion in stable insoluble metal phosphate minerals. Consequently, stabilization experiment was an effective way to reduce the risk of hazardous metals in fly ash to the environment. 


\section{Acknowledgements}

Financial support for this work, provided by Ministry of housing and urban-rural development of the China (No. 2013-K4-27), are gratefully acknowledged.

\section{References}

[1] Haiying Zhang, Youcai Zhao, Jingyu Qi. Process Safety and Environmental Protection, 2010,(88):114-124.

[2] B.S. Crannell, T.T. Eighmy, J.E. Krzanowski, et al. Waste management, 2000, (20):135-148.

[3] S. Bhattacharyya, R.J. Donahoe, D.Patel. Fuel, 2009, 88(7):1173-1184.

[4] B.Bournonville, A.Nzihou, P.Sharrock, et al. Journal of Hazardous Materials, 2004, 116(1-2): 65-74.

[5] Zheng Shen, Xiang Dong, Peiling He. Journal of Nanjing Forestry University(Natural Sciences Edition), 2010, 6: 100-104. (In Chinese)

[6] Sukandar, T.Padmi, M.Tanaka, et al. Waste management, 2009, (29):2065-2070.

[7] Shaohua Hu. Journal of hazardous materials, 2005, (B123):158-164.

[8] A.Nzihou, P.Sharrock. Waste management,2002,(22):235-239. 